\title{
PENGARUH BAURAN PEMASARAN DAN CITRA DESTINASI TERHADAP MINAT BERKUNJUNG KEMBALI DI DESA WISATA SELO PARK NGANJUK
}

\author{
Budi Susanto \\ Fakultas Ekonomi, Universitas Kadiri \\ budi_susanto@unik-kediri.ac.id
}

\section{Nursamsu}

Fakultas Ekonomi, Universitas Kadiri

nursamsu@unik-kediri.ac.id

\begin{abstract}
The purpose of this study was to determine the effect of Marketing Mix and Destination Imagery on the Interest of Returning Tourists in Selo Park Jatikalen Nganjuk. The study sample was taken as many as 100 respondents from visitors to Selo Park Jatikalen Nganjuk. The analytical tools used in this study are instrument analysis, validity test, reliability test, classic assumption test, multiple linear analysis and hypothesis testing. The results showed that the influence of the Marketing Mix had a significantly positive effect on the interest of returning tourists to Selo Park. The results showed that the influence of Citra Destination had a significant positive effect on the interest of returning tourists to Selo Park. Both of these variables also affect together the Interest of Revisiting Selo Park attractions. Based on the results of this study, the manager of Selo Park tourism object can increase the Interest of Tourist Return Visit by increasing the Marketing Mix and Destination Image variable, because the increasing of these two variables is increasing the Interest of Selo Park Tourist Returning Visit.
\end{abstract}

Keywords: Marketing Mix, Destination Image and Revisit Intention

\section{PENDAHULUAN}

Pariwisata merupakan salah satu sektor yang sedang berkembang pada saat ini, dimana peranan pariwisata itu sendiri sebagai salah satu tujuan untuk menenangkan pikiran,kesenangan dan melepas kejenuhan dari kegiatan sehari-hari. Salah satu destinasi wisata yang sering di kunjungi di Kabupaten Nganjuk Jawa Timur diantaranya wisata air terjun Sedudo yang berlokasikan di Desa Ngliman Kecamatan Sawahan, bahkan wisata air terjun Sedudo ini sudah sangat terkenal hingga manca Negara. Selain air terjun Sedudo masih banyak destinasi tempat wisata yang bias dikunjungi untuk berlibur yaitu wisata taman Roro Kuning di Desa Bajulan Kecamatan Ngepeh, bukit Batu yang terdapat di Desa Margopatut Kecamatan Sawahan, air terjun Singokromo, wisata Watu Lawang, situs Sadepok yang bertempat di Ngganter tempatnya 10KM sebelum puncak
Gunung Wilis. Sawahan menjadi lokasi wisata terbanyak di Kabupaten Nganjuk.

Pada tahun 2019 Kabupaten Nganjuk juga menambah destinasi lokasi wisatanya yakni waduk Selo Park. Dari sekian banyak tempat pariwisata yang terdapat di Kabupaten Nganjuk semuanya bertempat di pedesaan lokasinya penuh dengan pepohonan airnya juga masih sangat jernih jadi banyak wisatawan yang datang untuk berlibur di Kabupaten Nganjuk karena lokasinya tersebut dan bahkan pemerintahan Kabupaten Nganjuk pada tahun 2021 nanti akan membuka atau meresmikan waduk tempat wisata terbesar se Asia Tenggara yakni waduk Semantok yang berlokasikan di perbatasan Rejoso, Gondang dan Bojonegoro. Pada bulan Februari 2019 Dinas Pariwisata Provinsi Jawa Timur mencatat bahwa Kabupaten Nganjuk masuk kedalam 10 besar Kabupaten dengan lokasi wisata terbanyak di Provinsi Jawa Timur. 
Diantara sekian banyak tempat wisata di Kabupaten Nganjuk, saat ini yang tengah banyak di kunjungi wisatawan baik dari dalam maupun luar kota yaitu wisata Selo Park. Selo Park ini juga menjadi salah satu destinasi terbaru tempat wisata yang ada di Kabupaten Nganjuk. Tempat wisata ini diharapkan mampu meningkatkan perekonomian warga masyarakat sekitar. Wakil Bupati Kabupaten Nganjuk Dr. Drs. Marhaen Djumadi SE. SH. MH. MBA mengatakan, " Sesuai dengan visi kita, bagaimana kita mengembangkan pariwisata di Kabupaten Nganjuk sehingga dengan wisata yang berkembang dapat meningkatkan Pendapatan Asli Daerah ( PAD ) di Kabupaten Nganjuk, apabila PAD nya meningkat maka kesejahteraan masyarakat kita juga meningkat ".("Wisata Selo Park Jatikalen, Wilayah Destinasi Terluas di Nganjuk - Kabar Nganjuk," n.d.)

Pada saat peresmian Selo Park ini pengelola tempat wisata tersebut menyiapkan 8000 tiket masuk dan semuanya habis terjual. Banyak para wisatawan menyampaikan pendapat bahwa Selo Park ini merupakan tempat wisata yang sangat cocok untuk dijadikan tempat berlibur karena udaranya sangat sejuk, banyak tempat bermain untuk anak - anak, coffee break, tempat makan dsb. Disediakannya tempat penginapan dan harga tiketnya yang terjangkau membuat para wisatawan banyak yang mengunjungi kembali tempat tersebut. ("Pria Nganjuk Ini Ubah Bekas Tanah Tambang yang Tandus Jadi Taman Selopark di Desa Wisata Perning - Surya," n.d.) Menurut (Owomoyela, S. K., Olasnkanmi, S., \& Oyeniyi, K. O ,2013), "yang berjudul "Investigating The Impact of Marketing Mix Elements on Consumer Loyalty : An Emprical Study on Nigeian Breweries Plc" yang bertujuan untuk mengetahui efek elemen bauran pemasaran (marketing mix) terhadap loyalitas konsumen. Persamaan dengan penelitian ini yaitu menggunakan analisis bauran pemasaran (marketing mix) dalam mengejar tujuan pemasaran. . Hasil penelitian yang dilakukan adalah menyelidiki dampak dari elemen bauran pemasaran (marketing mix) terhadap loyalitas konsumen bahwa harga, produk, tempat dan promosi dapat memprediksi loyalitas konsumen".("Perencanaan Strategi Pemasaran Dengan Pendekatan Bauran Pemasaran Dan Swot Pada Perusahaan Popsy Tubby $\mid$ Amalia | Performa,” N.D.)
Selo Park ini memiliki luas hingga 300 hektar menyajikan berbagai macam wahana, baik untuk dewasa,remaja dan anak - anak. Tiket untuk masuk sangat terjangkau dengan Rp10.000 pengunjung sudah bisa masuk ke objek wisata terbesar di Nganjuk. Tempat ini juga sangat cocok untuk dijadikan sebagai objek foto karena banyak bunga berbagai warna yang terdapat di Selo Park ini. Bunga - bunga. yang ditata dengan rapi dan terdapat taman yang di kelilingi pohon cemara pastinya akan membuat para pengunjung ingin datang kembali.

Lokasi wisata Selo Park bertempat di Desa Perning, Kec. Jatikalen, Kabupaten Nganjuk yang di resmikan pada tanggal 5 Januari 2019, lokasinya kurang lebih 30KM dari Nganjuk kota. Untuk dapat sampai di lokasi ini para pengunjung bias membawa kendaraanya sampai di lokasi karena akses jalanya yang mudah dan aman. Akses jalan ke Selo Park ini bisa menggunakan kendaraan roda dua, empat maupun bus, karena di lokasi wisata sudah disediakan area parkir yang sangat luas.

Selain tempatnya yang bersih juga terdapat fasilitas lain diantaranya, terdapat warung makan yang menyajikan berbagai macam makanan khas Nganjuk yang pasti harganya sangat terjangkau, higenis, halal dan aman. Selain itu terdapat pula beberapa restouran yang menyajikan makanan - makanan modern. Bisa dikatakan tempat wisata ini merupakan tempat wisata yang fasilitasnya lengkap karena selain warung makan dan restouran tadi masih terdapat caffe untuk para remaja, tempat beribadah, kamar mandi umum yang bersih dan luas, hotel penginapan yang murah dan kualitasnya sangat baik. Akan tetapi selain kelebihan dari wisata Selo Park tadi ada beberapa hal yang harus di perbaiki diantaranya arah penunjuk jalan atau plang yang masih sedikit, resapan air yang kurang dan penerangannya masih sedikit. Sedangkan di air terjun sedudo pada bulan Mei listrik sudah masuk ke wilayah tersebut, tak kalah dengan air terjun Sedudo Selo Park ini mengutamakan keindahan alam, keasrian dan airnya yang sangat jernih.

Dari uraian di atas, maka penelitian ini bertujuan untuk mengetahui pengaruh Bauran Pemasaran dan Citra Destinasi terhadap Minat Berkunjung Kembali di desa wisata Selopark Nganjuk. 


\section{METODOLOGI PENELITIAN}

\section{Populasi, Sampel dan Teknik Pengambilan Sampel}

Populasi dalam penelitian ini adalah para wisatawan yang berkunjung di wisata Selo Park Kabupaten Nganjuk pada bulan September sampai November 2019.Sampel Kuesioner yang di sebarkan di tempat wisata Selo Park sebanyak 100 (Sugiyono 2010: 217).

Terdapat teknik dalam pengambilan sampel untuk melakukan penelitian, menurut (Sugiyono,2017:81) menjelaskan bahwa teknik sampel mrupakan teknik pengambilan sampel untuk menentukan sampel yang akan digunakan dalam penelitian, terdapat beberapa teknik sampling yang digunakan. Teknik sampling dibagi menjadi dua kelompok yaitu probability sampling dan non probability sampling. Pada penelitian ini, peneliti menggunakan probability sampling.

Menurut (Sugiyono,2017:82) "probability sampling adalah teknik pengambilan sampel yang memberikan peluang atau kesempatan yang sama bagi setiap unsur atau anggota populasi untuk dipilih menjadi sampel". Probability sampling terdiri dari simple random sampling, proponate stratified random sampling, disproportionate stratified random, sampling area (cluster) sampling. Pada penelitian ini peneliti menggunakan simple random sampling, kemudian menurut (Sugiyono,2017:82) Simple Random Sampling adalah pengambilan anggota sampel dari populasi yang dilakukan secara acak tanpa memperhatikan strata yang ada dalam populasi itu.

\section{Metode Pengumpulan Data}

Melakukan pengumpulan data informasi melalui wawancara kepada responden yang ditemui di lokasi penelitian dan pengumpulan data tersebut digunakan untuk pembuatan pertanyaan pada kuisioner yang akan diisi oleh responden yaitu wisatawan selopark.

\section{Metode Analisis}

Pada penelitian yang akan dilakukan pada analisa di penelitian ini yaitu dengan analisis kuantitatif dengan menggunakan aplikasi SPSS versi 23 IBM diawali dengan pengujian instrument validitas dan reliabilitas kuesioner dengan asumsi jika data yang diuji memiliki nilai valid $\alpha<0.05$ kemudian pada nilai reliabel dengan asumsi cronbach alpha < 0.6 dengan asumsi model regresi linier sebagai berikut :

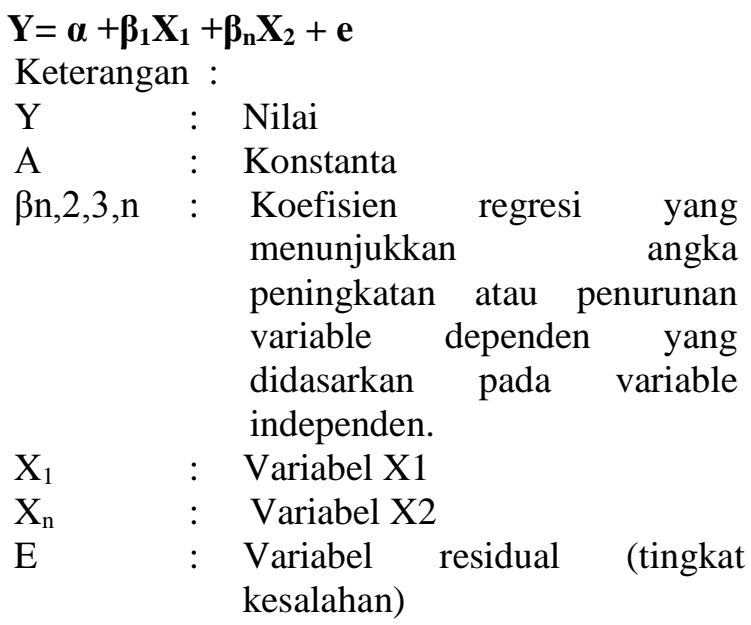

Selanjutnya dilakukan pengujian hipotesis yang meliputu uji $\mathrm{F}$ dan Uji $\mathrm{T}$ serta Analisis Koefisien Determinasi

\section{HASIL DAN PEMBAHASAN}

\section{Uji Validitas}

Tabel 1 Uji Validitas

\begin{tabular}{l|l|l|l}
\hline Item & R hitung & R tabel & keterangan \\
\hline X1.1 & 0.765 & 0,206 & Valid \\
\hline X1.2 & 0.478 & 0,206 & Valid \\
\hline X1.3 & 0.342 & 0,206 & Valid \\
\hline X1.4 & 0.742 & 0,206 & Valid \\
\hline X1.5 & 0.671 & 0,206 & Valid \\
\hline X1.6 & 0.753 & 0,206 & Valid \\
\hline X1.7 & 0.820 & 0,206 & Valid \\
\hline X1.8 & 0.634 & 0,206 & Valid \\
\hline X1.9 & 0.475 & 0,206 & Valid \\
\hline X1.10 & 0.778 & 0,206 & Valid \\
\hline X1.11 & 0.569 & 0,206 & Valid \\
\hline X1.12 & 0.683 & 0,206 & Valid \\
\hline X1.13 & 0.595 & 0,206 & Valid \\
\hline X1.14 & 0.543 & 0,206 & Valid \\
\hline X1.15 & 0.665 & 0,206 & Valid \\
\hline X1.16 & 0.619 & 0,206 & Valid \\
\hline X1.17 & 0.706 & 0,206 & Valid \\
\hline X1.18 & 0.757 & 0,206 & Valid \\
\hline X1.19 & 0.772 & 0,206 & Valid \\
\hline X1.20 & 0.685 & 0,206 & Valid \\
\hline X1.21 & 0.449 & 0,206 & Valid \\
\hline X1.22 & 0.668 & 0,206 & Valid \\
\hline X2.1 & 0.826 & 0,206 & Valid \\
\hline X2.2 & 0.775 & 0,206 & Valid \\
\hline X2.3 & 0.867 & 0,206 & Valid \\
\hline X2.4 & 0.768 & 0,206 & Valid \\
\hline X2.5 & 0.615 & 0,206 & Valid \\
\hline & & &
\end{tabular}




\begin{tabular}{c|l|l|l}
\hline Y1.1 & 0.650 & 0,206 & Valid \\
\hline Y1.2 & 0.725 & 0,206 & Valid \\
\hline Y1.3 & 0.527 & 0,206 & Valid \\
\hline Y1.4 & 0.586 & 0,206 & Valid \\
\hline Y1.5 & 0.743 & 0,206 & Valid \\
\hline Y1.6 & 0.726 & 0,206 & Valid \\
\hline Y1.7 & 0.799 & 0,206 & Valid \\
\hline
\end{tabular}

Pada uji Validitas digunakan untuk menguji apakah atribut- atribut yang sudah diisi oleh responden memiliki hasil yang valid atau tidak. Dari tabel diatas diperoleh hasil perhitungan bahwa seluruh item kuesioner memiliki nilai nilai $r$ hitung yang seluruhnya lebih besar dari $r$ tabel, sehingga seluruh item dinyatakan valid.

\section{Uji Reliabilitas}

Tabel 2 Uji Reliabilitas

\begin{tabular}{l|l|l|l}
\hline Variabe & $\begin{array}{l}\text { Alpha } \\
\text { cronbachs }\end{array}$ & $\begin{array}{l}\text { Batas } \\
\text { kritis }\end{array}$ & Keterangan \\
\hline $\begin{array}{l}\text { Bauran } \\
\text { Pemasaran }\end{array}$ & 0.755 & 0.60 & Reliabel \\
\hline $\begin{array}{l}\text { Citra } \\
\text { Destinasi }\end{array}$ & 0.799 & 0.60 & Reliabel \\
\hline $\begin{array}{l}\text { Minat } \\
\text { Kunjung } \\
\text { Kembali }\end{array}$ & 0.765 & 0.60 & Reliabel \\
\hline
\end{tabular}

Setelah dilakukan uji validitas, dilakukan uji reliabilitas berfungsi untuk mengetahui tingkat reliabel dari atribut tersebut. Didalam uji reliabilitas dilakukan dengan Uji Cronbach Alpha sebesar > 0,6 untuk mencapai tingkat reliabel. Dari hasil perhitungan dipperoleh bahwa keseluruhan variabel memeiliki nilai alpha cronbach's diatas 0,6. Sehingga sleuruh item dinyatakan reliabel.

\section{Uji Regresi Linier Berganda}

Tabel 3 Variabel Entered/ Removed Coefficients $^{\mathrm{a}}$

\begin{tabular}{|c|c|c|c|c|c|c|}
\hline & & \multicolumn{2}{|c|}{$\begin{array}{l}\text { Unstandardized } \\
\text { Coefficients }\end{array}$} & $\begin{array}{l}\text { Standardized } \\
\text { Coefficients }\end{array}$ & $\mathrm{t}$ & Sig. \\
\hline \multicolumn{2}{|c|}{ Model } & B & Std. Error & Beta & & \\
\hline \multirow[t]{3}{*}{1} & (Constant) & 3.862 & 2.386 & & 1.619 & .110 \\
\hline & $\begin{array}{l}\text { Bauran } \\
\text { Pemasara } \\
\mathrm{n}\end{array}$ & .169 & .033 & .485 & 5.146 & .000 \\
\hline & $\begin{array}{l}\text { Citra } \\
\text { Destinasi }\end{array}$ & .526 & .131 & .379 & 4.018 & .000 \\
\hline
\end{tabular}

Dari hasi pengujian didapatkan persamaan regresi sebagai berikut :

$\mathrm{Y}=3,862+0.169 \mathrm{X} 1+0.526 \mathrm{X} 2$

Persamaan tersebut dapat diuraikan sebagai berikut :

a) Konstanta $\mathrm{a}=3,862$ artinya apabila Bauran Pemasaran dan Citra Destinasi sama dengan 0 atau tidak berubah maka Minat Berkunjung Kembali akan bernilai 3,862.

b) Nilai koefisien Bauran Pemasaran sebesar 0,169 . Berarti bahwa setiap kenaikan satu nilai pada Bauran Pemasaran maka Minat Berkunjung Kembali akan bernilai 0,169.

c) Nilai koefisien Citra Destinasi sebesar 0,526 . Berarti bahwa setiap kenaikan satu nilai pada Citra Destinasi maka Minat Berkunjung Kembali akan bernilai 0,526.

Tabel 4 Hasil Uji T

Coefficients $^{\mathrm{a}}$

\begin{tabular}{|c|c|c|c|c|c|c|}
\hline & & & thicient & & & \\
\hline & & & & Standar & & \\
\hline & & $\begin{array}{r}\text { Unstan } \\
\text { Coeff }\end{array}$ & $\begin{array}{l}\text { rdized } \\
\text { ients }\end{array}$ & $\begin{array}{l}\text { Coeffic } \\
\text { ients }\end{array}$ & $\mathrm{t}$ & Sig. \\
\hline & del & & $\begin{array}{l}\text { Std. } \\
\text { Error }\end{array}$ & Beta & & \\
\hline 1 & (Constant) & 3.862 & 2.386 & & 1.619 & .110 \\
\hline & $\begin{array}{l}\text { Bauran } \\
\text { Pemasaran }\end{array}$ & .169 & .033 & .485 & 5.146 & .000 \\
\hline & $\begin{array}{l}\text { Citra } \\
\text { Destinasi }\end{array}$ & .526 & .131 & .379 & 4.018 & .000 \\
\hline
\end{tabular}

b. Dependent Variable: Minat Berkunjung K.

Sumber: Data primer yang diolah peneliti (2019)

Berdasarkan Hasil pengujian diperoleh hasil bahwa bauran pemasaran memiliki $t$ hitung sebesar 5.146 dengan nilai signifikasi sebesar $0.000>0.05$ maka hal ini menunjukan bahwa hipotesis yang menyatakan bahwa bauran pemasaran berpengaruh terhadap minat berkunjung kembali (H1) diterima.

Selanjutnya hipotesis yang menyatakan Hasil pengujian diperoleh hasil bahwa Citra Destinasi memiliki $\mathrm{t}$ hitung sebesar 4.018 dengan nilai signifikasi sebesar $0.000>0.05$ maka hal ini menunjukan bahwa hipotesis yang menyatakan bahwa bauran pemasaran berpengaruh terhadap minat berkunjung kembali (H2) diterima.

\section{Tabel 5 Hasil Uji F}

\begin{tabular}{lc|r|c|c|c}
\multicolumn{7}{c}{ ANOVA $^{\text {a }}$} \\
Model & $\begin{array}{c}\text { Sum of } \\
\text { Squares }\end{array}$ & df & $\begin{array}{c}\text { Mean } \\
\text { Square }\end{array}$ & F & Sig. \\
\hline $\begin{array}{l}1 \text { Regres } \\
\text { sion }\end{array}$ & 777.372 & 2 & 388.686 & 46.042 & $.000^{\mathrm{b}}$ \\
\hline
\end{tabular}




\begin{tabular}{lr|r|r|r|r}
\hline $\begin{array}{l}\text { Residu } \\
\text { al }\end{array}$ & 565.613 & 67 & 8.442 & & \\
\hline Total & 1342.986 & 69 & & \\
\hline
\end{tabular}

a. Dependent Variable: Minat Berkunjung Kemba

c. Predictors: (Constant), Citra Destinasi, Bauran Pemasaran

Sumber: Data primer yang diolah peneliti (2019)

Tabel 4.8 di atas, diperoleh $\mathrm{f}$ hitung sebesar 46.042 dengan signifikasi sebesar $0.000<0.05$, maka dapat disimpulkan bahwa Hipotesis yang menyatakan bahwa bauran pemasaran dan citra destinasi secara simultan berpengaruh terhadap minat berkunjung kembali (H3) diterima.

\subsubsection{Koefisien Determinasi}

\section{Tabel 4.9 Koefisien Determinasi}

\begin{tabular}{|c|c|c|c|c|c|}
\hline \multicolumn{6}{|c|}{ Model Summary ${ }^{\mathbf{b}}$} \\
\hline Model & $\mathrm{R}$ & $\begin{array}{c}\mathrm{R} \\
\text { Square }\end{array}$ & $\begin{array}{l}\text { Adjusted } \\
\text { R Square }\end{array}$ & $\begin{array}{c}\text { Std. } \\
\text { Error of } \\
\text { the } \\
\text { Estimate }\end{array}$ & $\begin{array}{l}\text { Durbin- } \\
\text { Watson }\end{array}$ \\
\hline 1 & $.761^{\mathrm{a}}$ & .579 & .566 & 2.906 & 1.861 \\
\hline
\end{tabular}

Sumber: Data primer yang diolah peneliti (2019)

Berdasarkan hasil diatas diperoleh angka R2 (R square) sebesar 0.579 atau $57,9 \%$, dengan demikian hasil tersebut menunjukan bahwa kemampuan variabel independent dalam menjelaskan variabel dependent sebesar 57,9\%, sedangkan sisanya dipengaruhi variabel lain yang tidak dikaji dalam penelitian ini.

\section{PEMBAHASAN}

\section{Pengaruh Bauran Pemasaran Terhadap Minat Berkunjung Kembali}

Berdasarkan hasil pengujian dapat disimpulkan dengan jelas bahwa bauran pemasaran berpengaruh terhadap minat berkunjung kembali. Semakin baik promosi dengan banyaknya potongan harga yang ditawarkan, produk lokal yang ditawarkan, tempanya yang strategis, petugas yang sangat ramah, pelayanan yang cepat, suasana dan tata letaknya yang bagus membuat wisatawan tertarik untuk berkunjung kembali di tempat tersebut. Hal ini mendukung penelitian sebelumnya yang dilakukan oleh (Rambe, 2014) yang menyatakan bahwa bauran pemasaran berpengaruh terhadap minat berkunjung kembali.

Pengaruh Citra Destinasi Terhadap Minat Berkunjung Kembali

Berdasarkan hasil pengujian dapat disimpulkan dengan jelas bahwa citra destinasi berpengaruh terhadap minat berkunjung kembali. Akses yang mudah dijangkau, keindahan alam yang terus dikembangkan, fasilitas yang disediakan semakin lengkap, tempatnya yang selalu ramai pengunjung untuk datang kembali mengunjungi tempat wisata tersebut. Hal ini mendukung penelitian sebelumnya yang dilakukan oleh Verissa Rana Khansa \& Naili Farida yang menyatakan bahwa citra destinasi berpengaruh terhadap minat berkunjung kembali.

Pengaruh Bauran pemasaran dan Citra Destinasi Terhadap Minat Berkunjung Kembali

Berdasarkan hasil pengujian dapat disimpulkan dengan jelas bahwa bauran pemasaran dan citra destinasi berpengaruh terhadap minat berkunjung kembali. Hal ini mendukung penelitian sebelumnya yang dilakukan oleh Titing Kartika, Nurull Rochmah Paramadika \& Apay Safari 2016.

\section{KESIMPULAN}

Bauran Pemasaran berpengaruh signifikan terhadap Minat Berkunjung Kembali di Selo Park,. Besarnya nilai $\mathrm{t}$ hitung yang dimiliki Bauran Pemasaran dalam mempengaruhi Minat Berkunjung Kembali wisatawan adalah sebesar 5.146.

Citra Destinasi berpengaruh signifikan terhadap Minat Berkunjung Kembali di Selo Park,. Besarnya nilai $t$ hitung yang dimiliki Citra Destinasi dalam mempengaruhi Minat Berkunjung Kembali wisatawan adalah sebesar 4.018 .

Bauran Pemasaran dan Citra Destinasi berpengaruh secara signifikan terhadap Minat Berkunjung Kembali di Selo Park. Besarnya nilai $f$ hitung yang dimiliki Bauran Pemasaran dan Citra Destinasi dalam mempengaruhi Minat Berkunjung Kembali wisatawan adalah sebesar 46.042. Nilai koefisien determinasi menunjukkan bahwa kemampuan bauran pemasaran dan citra destinasi dalam menjelaskan minat berkunjung kembali sebesar $57.9 \%$. 


\section{Saran}

Saran yang dapat disampaikan berdasarkan kesimpulan di atas adalah sebagai berikut :

Terkait dengan Bauran Pemasaran yang memberikan pengaruh sebesar 5.146 terhadap Minat Berkunjung Kembali pada penelitian ini, maka disarankan pengelola tempat wisata mempertahankan Bauran Pemasaran terlebih pada mengoptimalkan indikator Bukti Fisik destinasi wisata yang telah memiliki total skor yang paling tinggi diantara indikator lainnya. Perbaikan fasilitas-fasilitas pada destinasi wisata secara berkala guna meningkatkan kembali nilai Bauran Pemasaran dan memperbanyak acara yang dapat menarik pengunjung untuk datang kembali ke Selo Park.

Terkait dengan Citra Destinasi yang memberikan pengaruh sebesar 4.018 terhadap Minat Berkunjung Kembali, maka bagi pengelola hendaknya lebih mengoptimalkan indikator keindahan alamnya di destinasi wisata, untuk meningkatkan pengaruh Citra Destinasi. Salah satu cara yang mungkin dilakukan adalah terus mengembangkan dan menjaga keindahan alam, hal ini mampu meningkatkan Minat Berkunjung Kembali wisatawan di Selo Park.

Terkait dengan Bauran Pemasaran dan Citra Destinasi memberikan pengaruh sebesar 46.042 terhadap Minat Berkunjung Kembali maka bagi pengelola hendaknya meningkatkan indikator bukti fisik dan keindahan alam yang mampu meningkatkan Minat Berkunjung Kembali wisatawan di Selo Park.

Dari hasil penelitian diketahui adanya pengaruh signifikan Bauran Pemasaran terhadap Minat Berkunjung Kembali wisatawan di Selo Park dengan pengaruh sebesar 51.5\%. Oleh karenanya bagi peneliti yang ingi meneliti tentang Minat Berkunjung Kembali wisatawan di Selo Park dapat menambahkan variable lainnya seperti kualitas pelayanan, kualitas daya Tarik wisata, word of mouth, dan sebagainya.

\section{DAFTAR PUSTAKA}

Aprianto, R. (2016). Pengaruh Promosi Dan Pelayanan Terhadap Kepuasan Pelanggan Pada Toko Bnj Elektronik. Pemasaran, 02(01), 41-63.

Aviolitasona, G. B. (2017). Pengaruh Citra Destinasi Terhadap Minat Kunjung
Ulang Wisatawan Umbul Sewu Pengging, Boyolali, 1-14.

Kajian Pustaka, K. P. D. H. (2010). Bab 2pemikiran Dan Hipotesis.

Landasan Teori Dan Kerangka Pemikiran. (N.D.).

Perencanaan Strategi Pemasaran Dengan Pendekatan Bauran Pemasaran Dan Swot Pada Perusahaan Popsy Tubby | Amalia | Performa. (N.D.). Retrieved December 20, 2019, From Https://Journal.Uc.Ac.Id/Index.Php/Perfo rma/Article/View/172

Pria Nganjuk Ini Ubah Bekas Tanah Tambang Yang Tandus Jadi Taman Selopark Di Desa Wisata Perning - Surya. (N.D.). Retrieved December 20, 2019, From Https://Surabaya.Tribunnews.Com/2019/ 11/11/Pria-Nganjuk-Ini-Ubah-BekasTanah-Tambang-Yang-Tandus-JadiTaman-Selopark-Di-Desa-WisataPerning

Rambe, O. I. (2014). Pengaruh Bauran Pemasaran Jasa Terhadap Minat Berkunjung Kembali Ke Wonders Water World Waterpark Cbd Polonia Medan.

Titing, K., Rochmah, P. N., \& Apay, S. (2016). Pengaruh Bauran Pemasaran Terhadap Keputusan Berkunjung Wisatawan Di Lawangwangi Creative Space- Dago Giri Bandung, (L), 12-24.

Wisata Selo Park Jatikalen, Wilayah Destinasi Terluas Di Nganjuk - Kabar Nganjuk. (N.D.). Retrieved December 20, 2019, From Https://Kabarnganjuk.Com/WisataSelo-Park-Jatikalen-Wilayah-DestinasiTerluas-Di-Nganjuk/

Yani, P. (2014). Pengaruh Bauran Pemasaran Jasa Terhadap Keputusan Konsumen Mengunjungi Pariwisata Pulau Cubadak Di Tarusan Pesisir Selatan. 